\title{
5 Research Square

\section{Changes in Particle Size Distribution in Hydroponic Lagoons Working as A Third Stage of Wastewater Treatment}

\author{
Aleksandra Bawiec ( $\nabla$ aleksandra.bawiec@upwr.edu.pl ) \\ Wroclaw University of Environmental and Life Sciences \\ Katarzyna Pawęska \\ Wroclaw University of Environmental and Life Sciences \\ Krzysztof Pulikowski \\ Wroclaw University of Environmental and Life Sciences \\ Kinga Marek \\ Wroclaw University of Environmental and Life Sciences
}

\section{Research Article}

Keywords: particle size analysis, wastewater treatment, granulometric composition, laser granulometry, hydroponic lagoon, fractal dimension

Posted Date: December 16th, 2020

DOI: https://doi.org/10.21203/rs.3.rs-126773/v1

License: (9) This work is licensed under a Creative Commons Attribution 4.0 International License. Read Full License 


\section{Abstract}

The aim of research was to evaluate changes in the particle size distribution in two hydroponic lagoons working as a third stage of wastewater treatment where purification processes are based on plants and algae activity. Wastewater samples were taken during the winter and summer half of the year. In the samples taken from analyzed hydroponic lagoons the range of particles size was very wide (0.01 $1000.0 \mu \mathrm{m})$. In both of the research facilities, the fractal dimension (Df) of particles was close to 2.0 what decides about developed surface of the particles. The results may indicate the predominance of algae cells in the total amount of suspensions. This information may pay a key role in determination the impact of discharged particles on the receiving water bodies quality as well as can be the main factor that allows to improve the system of suspended solids removal.

\section{Introduction}

Due to high risk of eutrophication in surface water reservoirs - natural ponds, lakes, artificial reservoirs and even seas - limiting the inflow of nitrogen and phosphorus compounds should be currently the priority ${ }^{1,2}$. Among the sources of nutrients getting into surface waters we can distinguish linear, surface and point sources. Linear sources are mainly roads whose highly sealed surface generates surface runoff washing contaminants into the trenches and then to surface water ${ }^{3}$. The largest percentage of pollutants flowing down the roads are suspensions carrying a nitrogen and phosphorus load as well as the nitrogen compounds from fertilizers derived from arable lands nearby the roads ${ }^{4,5}$. The main surface sources of nutrients are agricultural lands where the use of mineral and organic fertilizers rich in $\mathrm{N}$ and $\mathrm{P}$ is a common action. The threat of watercourses and surface water enrichment in nutrients is high especially during early spring when fertilizers are used ${ }^{6}$. Point sources of nitrogen and phosphorus that enter surface waters include, above all, sewage discharges from wastewater treatment plants (WWTP) ${ }^{7}$. This source can be called one of the most important because the sewage flows into the receiver in a constant way and the amount of nutrients is subject to periodic analysis. What more the efficiency of $\mathrm{N}$ and $\mathrm{P}$ removal in WWTP is still increasing by the use of specific solutions.

One of the solutions invented for increased nitrogen and phosphorus removal is the use of additional wastewater purification after biological treatment. The common solution is the hydroponic system where aquatic plants are flowing on the wastewater surface planted on floating medium. This kind of floating islands (floating hydroponic root mats FHRMs) are successfully used for improvement of water quality in lakes or other reservoirs ${ }^{8}$. To remove excessive amount of $\mathrm{N}$ and $\mathrm{P}$ from sewage, a hydroponic ditch with aquatic plants floating on a floating islands can be used. The plants roots immersed into wastewater work as a filter for flowing sewage and provide suitable hydraulic conditions for contaminants uptake ${ }^{9}$. Additional treatment (3rd stage of wastewater treatment) with the use of artificial river is based on natural processes occurring in natural watercourses called self-purification. Reduction of nutrients and other contaminants concentrations in semi-natural purification systems is a result of plants, bacteria and other aquatic organisms activity ${ }^{10,11,12}$. Very often the role of algae in this kind of systems is omitted 
while their nutrient uptake capacity is very high ${ }^{13}$. As reported by Orfanos et al. ${ }^{14}$ algae are able to remove up to $97 \%$ of total phosphorus, $93 \%$ of phosphates and $99 \%$ nitrate nitrogen from secondary effluent from different kinds of industries.

Nowadays the algae based wastewater treatment methods are becoming more popular due to the complex purification process which consists of nutrient uptake and retention in algae cells with simultaneous ammonia stripping and oxygen enrichment ${ }^{15,16}$. At the same time high production on biomass and possibilities of its use for biofuel production is admittedly an additional advantage ${ }^{17}$.

Unfortunately the use of natural organisms in technology for 3rd stage of wastewater treatment may increase concentration of total suspended solids at the outflow from WWTP. Dead plant fragments, dead aquatic organisms and excess algae biomass that is not used for further purposes, may constitute a large percentage of suspended solids discharged into the receiver causing a threat for natural water ecosystem. The most problematic is removal of excess amount of algae because of their small size, negatively charged surface, small density and lipids storage in cells which make them permanently suspended in sewage ${ }^{18}$. Fast and easy method of total suspended solids characterization might be useful in development of new, effective methods of suspensions removal and reuse. Such method is laser granulometry that allows to measure particles size and dimensions, their distribution in wastewater as well as their shape and specific properties, e.g. the ability to react with other wastewater components ${ }^{19,20}$. Information about the size of suspended solids as well as their fractal dimensions gives the wider picture of the nature of purification processes occurring in hydroponic lagoons. On the basis of suspensions granulometric composition it is possible to assume their constitution to develop effective methods of their removal.

The aim of this study was to determine the granulometric composition and fractal dimensions of particles in wastewater after three stages of purification on the basis of research conducted in two wastewater treatment plants equipped with hydroponic lagoon.

\section{Materials And Methods}

\subsection{Research objects}

The samples of wastewater were collected from two hydroponic lagoons being the third stage of sewage treatment. The research objects (WWTP A and WWTP B) were located in the south-western part of Poland, $50^{\circ} 27^{\prime} \mathrm{N}, 17^{\circ} 00^{\prime} \mathrm{E}$ and $51^{\circ} 44^{\prime} \mathrm{N}, 15^{\circ} 35^{\prime} \mathrm{E}$. The designed capacity of object A was $2500 \mathrm{~m}^{3} / \mathrm{d}$ (PE 22 396) and $1625 \mathrm{~m}^{3} / \mathrm{d}$ for object $B$ with PE on the level of 11750 . Both of the research objects were designed and built on the circle plan where the treatment process take place under the roof. First stage of treatment is mechanical treatment with the use of Noggerath Spiral Sieve, second stage takes place in hybrid circulating biological reactor that combines activated sludge and biological membrane treatment method. Third stage of treatment is hydroponic lagoon built on the circumference of biological reactor. In WWTP A the main plant species were Pistia stratiotes, Myriophyllum verticillatum and Limnobium 
laevigatum while in WWTP B the two identified species were Calla pallustris and Lemna minor. The construction of hydroponic lagoons were slightly different. In object A, the lagoons length is $191.0 \mathrm{~m}$, width $=2.1 \mathrm{~m}$ and average depth is $1.4 \mathrm{~m}$. The walls and the roof covering the lagoon are made of polycarbonate shits to allow sunlight income and thermal insulation (Fig. 1). In the case of hydroponic ditch of object $B$, its length is $97.0 \mathrm{~m}$, width $=1.20 \mathrm{~m}$ and average depth is $1.45 \mathrm{~m}$. To ensure the supply of light necessary for the proper functioning of plants, windows were placed in the walls and roof above the lagoon (Fig. 2).

\subsection{Samples collection and measurement}

Wastewater samples were taken during the winter and summer half of the year from the several sampling points of hydroponic ditch - always from the inflow of biologically purified sewage, the middle points of the hydroponic lagoon and the outflow of treated wastewater (Figs. 3 and 4). In WWTP A the P1 point represents sewage clarified in secondary settling tank, P3 - sewage after flow through part of the ditch planted with macrophytes and two aerated sections, P4 - sewage after flow through the middle part of the lagoon without plants but with aerated sections and P6 - sewage after flow through planted section at the outflow of the lagoon. Last $10 \mathrm{~m}$ of the last section of the lagoon are not equipped with floating islands. In WWTP B the L1 point represents sewage after clarification in secondary settling tank, L2 after flow through the part of a ditch planted with Calla pallustris and the L3 - sewage at the outflow of the lagoon, after flow through the part of the lagoon without floating panels. In both objects, samples were collected from the same depth and with the same conditions of sewage flow through the lagoon.

After samples collection, $800 \mathrm{ml}$ of the wastewater sample was transported to the laboratory to test the granulometric composition of suspended solids in sewage with the use of the Malvern Mastersizer 2000 laser granulometer. To provide homogeneous probe for laser diffraction measurements, the Hydro MU dispersion paddle with stirrer was used. Each time, 30 measurements for one sample were made to get a representative number of results for analysis. The calculations of equivalent diameters and fractal dimensions were performed using an Excel spreadsheet prepared by Malvern Instruments Ltd., with a restricted computational procedure.

\section{Results And Discussion}

Calculations of particle size distribution showed that in all samples taken from hydroponic lagoons the range of particles size was very wide $(0.01-1000.0 \mu \mathrm{m})$. In WWTP $A$ the changes of particles diameters during the flow through the hydroponic ditch in the winter season, were not very noticeable especially in the first sections of the lagoon. It can be noticed that characteristics of particles diameters of two first sampling points - P1 and P3 - are nearly the same and $90 \%$ of particles had $d i=1.0$. Very noticeable increase in the share of particles with diameters lower than 1.0 occurred in the next sampling point - P4 - after flow through the part of the ditch without plants. The particles with di in a range $0.1-1.0 \mu \mathrm{m}$ are classified as microsuspensions that do not undergo sedimentation ${ }^{21}$. At the last sampling point (P6) the diameters increased and $90 \%$ reached sizes bigger than $5.0 \mu \mathrm{m}$ (Fig. 5.A). In the WWTP B similar 
tendency in two first sampling points was observed - in L1 and L2 points $90 \%$ of particles had diameters of $10 \mu \mathrm{m}$. At the outflow of the lagoon the di of particles decreased and the vast majority showed diameters smaller than $1.0 \mu \mathrm{m}$ (Fig. 5.B).

In the summer season particles diameters identified in hydroponic lagoon of WWTP A showed less variability than in the winter season (Fig. 6.A). The vast majority of particles in sewage samples from all sampling points had $d i$ in a range 1.0-10.0 $\mu \mathrm{m}$. It can be observed that there was a slight increase in particles diameters at the end sampling points. In the second research object (B) the constant increase of particles diameter was observed. At the inflow to the lagoon $90 \%$ of particles had $d i=10.0 \mu \mathrm{m}$, while in the outflow from the wastewater treatment plant (L3) diameters of $90 \%$ of particles reached $100 \mu \mathrm{m}$ (Fig. 6.B). Comparing the particles diameters from both of research object it can be concluded that in the hydroponic lagoon of WWTP A the particles diameters at the outflow of the lagoon were smaller than from WWTP B.

To determine the characteristics and structure of the suspended particles in sewage from hydroponic lagoons, the average equivalent diameters $(D i)$ were calculated. The $D(1.0)$ describes the average length of particles, the $D(2.0)$ - average surface, $D(3.0)$ average volume ${ }^{22}$. The $D(3.2)$ equivalent diameter is calculated on the basis of the volume ratio referred to the sum of particles surface and its value decides about the size of active surface of the particle. The bigger the $D(3.2)$, the surface of particles is smaller and they efficiency of chemical reactions catalysis decrease ${ }^{23}$. The size of $D(4.3)$ diameter informs about the location of gravity center in the particle and mass concentration of the particles in the solution. The value of $D(4.3)$ decides about sedimentation capacity of the particles ${ }^{24}$. The results of equivalent diameters calculations are presented in Table 1 - for WWTP A and Table 2 - WWTP B. 
Table 1

Equivalent diameters of particles identified in wastewater from hydroponic lagoon in WWTP A

\begin{tabular}{|llllll|}
\hline \multicolumn{5}{|c|}{ Winter season } \\
\hline & $\mathrm{D}(1.0)$ & $\mathrm{D}(2.0)$ & $\mathrm{D}(3.0)$ & $\mathrm{D}(3.2)$ & $\mathrm{D}(4.3)$ \\
P1 & 0.923 & 1.587 & 3.239 & 13.494 & 27.918 \\
P3 & 0.875 & 1.441 & 2.952 & 12.392 & 27.714 \\
\hline P4 & 0.160 & 0.188 & 0.281 & 0.624 & 2.544 \\
\hline P6 & 2.782 & 4.246 & 7.502 & 23.418 & 53.313 \\
\hline Summer season & & & \\
\hline P1 & 3.141 & 6.02 & 11.208 & 38.851 & 58.008 \\
\hline P3 & 2.698 & 4.011 & 8.139 & 33.517 & 76.443 \\
\hline P4 & 4.580 & 7.316 & 13.313 & 44.085 & 87.062 \\
\hline P6 & 4.232 & 6.480 & 10.849 & 30.414 & 57.508 \\
\hline
\end{tabular}

Table 2

Equivalent diameters of particles identified in wastewater from hydroponic lagoon in WWTP B

\begin{tabular}{|llllll|}
\hline \multicolumn{5}{|c|}{ Winter season } \\
\hline & $\mathrm{D}(1.0)$ & $\mathrm{D}(2.0)$ & $\mathrm{D}(3.0)$ & $\mathrm{D}(3.2)$ & $\mathrm{D}(4.3)$ \\
\hline L1 & 4.180 & 7.084 & 13.440 & 48.377 & 88.165 \\
\hline L2 & 4.368 & 7.220 & 13.203 & 44.152 & 78.340 \\
\hline L3 & 0.325 & 0.410 & 0.704 & 2.080 & 6.896 \\
\hline Summer season & & & \\
\hline L1 & 5.909 & 9.268 & 15.839 & 46.264 & 87.049 \\
\hline L2 & 21.966 & 27.907 & 41.586 & 92.343 & 213.839 \\
\hline L3 & 54.865 & 62.004 & 73.682 & 104.051 & 167.563 \\
\hline
\end{tabular}

In the winter season in hydroponic lagoon of research object $A$, the identified $D(1.0)$ diameters varied from 0.160 to $2.782 \mu \mathrm{m}$. The average length of particles from P1 to P4 sampling points was decreasing and then increased to almost $3.0 \mu \mathrm{m}$ at the outflow. $\mathrm{D}(2.0)$ equivalent diameter reached the highest value at the outflow from the lagoon when it reached $4.246 \mu \mathrm{m}$. During the flow through the ditch also $\mathrm{D}(3.0)$ diameters changed - at the inflow $\mathrm{D}(3.0)=3.239$ when at the outflow $-7.502 \mu \mathrm{m}$. $\mathrm{D}(3.2)$ also increased during the flow through the ditch from $13.494 \mu \mathrm{m}$ to $23.418 \mu \mathrm{m}$. This change indicates that the reactivity 
of the particles at the outflow of the lagoon was smaller than reactivity of particles in biologically treated wastewater. Similar tendency of $D i$ changes was observed in the case of all calculated equivalent diameters (also the $\mathrm{D}(4.3)$ ) - the diameters decreased during the flow through the first two sections of the lagoon and increased in the final section giving higher values at the outflow than at the inflow. Although the $D(4.3)$ values at the outflow were higher than at the inflow, they still suggested that the sedimentation capacity of the particles was low $(D(4.3)<50 \mu \mathrm{m})$.

During the summer season, the changes between equivalent diameters at the inflow and the outflow were almost imperceptible. They were slightly changing the P3 and P4 measuring point, when the decrease was noticeable. As in the winter season - the Di sizes increased during the flow through the last section of the hydroponic ditch but the final values were similar to the ones at the inflow. It can be noticed that during the warmer period, the Diwere higher than during the winter season. The reason might be connected with higher temperatures of wastewater what is the main factor affecting activity of microorganisms and algae.

In WWTP B the average length of identified particles in sewage from hydroponic lagoon expressed by $D(1.0)$ varied from $4.180 \mu \mathrm{m}$ at the inflow to $0.325 \mu \mathrm{m}$ at the outflow. The average surface described by $D(2.0)$ also decreased during the sewage flow in the lagoon from $7.084 \mu \mathrm{m}$ to $0.410 \mu \mathrm{m}$. In both described equivalent diameters, after flow through the first section of the ditch, slight increase of the $D i$ values was observed. The average volume of particles changed from $D(3.0)=13.440$ to $0.704 \mu \mathrm{m}$ but as well as in the case of $D(3.2)$ and $D(4.3)$ after the first section of lagoon there was a slight decrease in value and then after passing through the next stage increased by up to $95 \%$. Very small $D(3.2)$ value at the outflow $-2.080 \mu \mathrm{m}$ as well as very small $D(4.3)=6.896 \mu \mathrm{m}$ indicates, that particles in sewage flowing out of the wastewater treatment plant have bigger reactivity than at the inflow but still their sedimentation properties are bad.

During the summer season the tendency observed during the winter changed. In all cases

a very high increase in the value of equivalent diameters during the purification in 3rd stage of sewage treatment was observed. The average length, surface and volume of particles increased several dozen times what also affected sizes of $D(3.2)$ and $D(4.3)$ diameters. The efficiency of chemical reaction catalysis of the particles decreased because of the relatively high $\mathrm{D}(3.2)$ value that reached $104.051 \mu \mathrm{m}$. A positive aspect of the changes occurring in the hydroponic ditch is the increase in the diameter $D(4.3)$ and the improvement of the sedimentation capacity of the particles.

Average fractal dimensions of particles in wastewater from hydroponic lagoons were calculated to determine the spatial distribution of particles. According to Valle et al. ${ }^{25}$ the shape of particles with $D f$ close to 1.0 has linear character, $D f \approx 2.0$ is assigned to particles with more developed surface when the highest values that reach 3.0 are characteristic for particles more concentrated around the nucleus, with more extensive surface. The average fractal dimensions of particles identified in hydroponic lagoons during winter season are presented in Fig. 7 (A, B). 
Analyses of average fractal dimensions of particles in sewage from hydroponic ditch in WWTP A show that in all sampling points the $D f$ was close to 2.0 with coefficient of determination $\mathrm{R}^{2}$ on the level of more than 0.99 . The values decrease during the 3 rd stage of treatment but because of very small difference on the level of 0.063 (with the $\mathrm{R}^{2}=0.5323$ ) the changes of particles shape are not significant. In the case of fractal dimensions of particles in wastewater from WWTP B the tendency is similar - Df decrease during the treatment. Changes in fractal dimensions between inlet and outlet of the lagoon are more significant $\left(\mathrm{R}^{2}=0.7475\right)$ but the particles shape does not change diametrically. The highest $D f$ reached 2.080 and the lowest one -1.778 . To compare characteristics of particles identified in wastewater during winter and summer time, the $D f$ of particles measured in sewage samples taken during the summer season are presented in Fig. 8.

In the research object $A$ the average fractal dimensions of particles at the inflow and the outflow of the last stage of sewage purification were nearly the same and reached 2.330 (inflow) and 2.161 (outflow). Decrease of $D f$ value was observed in the second sampling point - P3 where it reached 1.859. For all calculated fractal dimensions the coefficient of determination $\mathrm{R}^{2}$ was higher than 0.99 what indicates very good match and hence - high accuracy of calculations ${ }^{26}$. In the case of WWTP B the decrease of fractal dimension after treatment in hydroponic lagoon was clearly noticeable - the $D f$ decreased from 2.149 to 1.089 what indicates changes in particles formation. At the outflow from the hydroponic ditch particles of suspended solids had linear shape as opposed to particles in biologically treated wastewater, whose surface was more extensive in space.

\section{Conclusions}

The analyses of granulometric composition of wastewater flowing through the hydroponic lagoons in two different wastewater treatment plants (WTTP A and WWTP B) in the summer and winter half of the year showed a lot of similarities. The changes observed between particles size and equivalent diameters from two objects might be connected with the differences of hydroponic ditch construction (length, depth, used plants). In the object with shorter hydroponic ditch the differences between amount and size of particles were more noticeable than in the longer one. In both of the objects the slight decrease of fractal dimension of particles was observed but still was close to 2.0. The $D f$ of particles close to 2.0 gives an information that the particles shape is not linear but have more developed surface. The particles with linear shape were identified only in the WWTP B in the summer season, where $D f$ decreased from 2.149 to 1.089 after wastewater flow through the lagoon.

Information about particles size, they reactivity and sedimentation capacity may pay a key role in determination the impact of discharged particles on the receiving water bodies quality as well as can be the main factor that allows to improve the system of suspended solids removal. In semi natural sewage purification systems like hydroponic lagoons particles characteristics is even more important because of the growth of algae that discharged into the receiving watercourses might be harmful for inhabitants of 
natural ecosystems. Comparing the data obtained in granulometric composition measurements with identification of algae species is the object of further Authors research.

\section{Declarations}

\section{Author contributions}

Aleksandra Bawiec wrote the main manuscript text and along with Katarzyna Pawęska prepared all the samples, measurements and analyzes with the help of Kinga Marek. Aleksandra Bawiec and Katarzyna Pawęska conceived the ideas and developed the methodological and analytical framework and interpreted the results. Krzysztof Pulikowski made the final edition of the manuscript. All authors reviewed the manuscript.

\section{Competing interests}

The authors declare no competing interests.

\section{References}

1. Grochowska, J., Tandyrak, R., Augustyniak, R., Łopata, M. \& Parszuto, K. Nutrient Balance of NorthEastern Poland Lakes in Polish River Basins and Lakes - Part I. The Handbook of Environmental Chemistry (ed. Korzeniewska, E. \& Harnisz., M.) 180-181 (Springer, 2020).

2. Räike, A., Taskinen, A. \& Knuuttila, S. Nutrient export from Finnish rivers into the Baltic Sea has not decreased despite water protection measures, Ambio 49, 460-474 (2020).

3. Geng, R. \& Sharpley, A.N. A novel spatial optimization model for achieve the trad-offs placement of best management practices for agricultural non-point source pollution control at multi-spatial scales. J. Clean. Prod. 234, 1023-1032 (2019).

4. Han, Y. et al. Changes of particulate matters during rain process and influence of that on chemical composition of precipitation in Hangzhou, China. China Environ. Sci. 33, 193-200 (2013).

5. Ni, D., Zhao, M., Wang, C. \& Shao, S. Characteristics and release of road runoff pollution under artificial rainfall intensity. IOP Conf. Series: Earth and Environmental Science. 358, 022064 (2019).

6. Pulikowski, K., Pawęska, K. \& Bawiec, A. Seasonal changes in phosphorus load flowing out of small agricultural catchments. J. Ecol. Eng. 16, 81-86 (2015).

7. Moriki, A., Antoniou, A., Savvidis, Y., Papadimitriou, C.A. \& Stoilas, V.O. Nutrient Limitation in a Coastal System Influenced by Mussel Farming, River Outflow and On-shore Circulation of Waters. Environ. Process. 6, 1019-1029 (2019).

8. Song, H.L., Li, X.N., Lu, X.W. \& Inamori, Y. Investigation of microcystin removal from eutrophic surface water by aquatic vegetable bed. Ecol. Eng. 35, 1589-1598 (2009).

9. Tanner, C.C. \& Headley, T. Floating treatment wetlands - an innovative solution to enhance removal of fine particulates, copper and zinc. The NZWWA J. 26-31 (2008). 
10. Boonchan, S., Britz, M.L. \& Stanley, G.A. Degradation and mineralization of high-molecular-weight polycyclic aromatic hydrocarbons by defined fungal bacterial cocultures. Appl Environ Microbiol. 66, 1007-1019 (2000).

11. Ye, J., Song, Z., Wang, L. \& Zhu, J. Metagenomic analysis of microbiota structure evolution in phytoremediation of a swine lagoon wastewater. Bioresour. Technol. 219, 439-444 (2016).

12. Saggaï, M.M., Ainouche, A., Nelson, M., Cattin, F. \& El Amrani, A. Long-term investigation of constructed wetland wastewater treatment and reuse: Selection of adapted plant species for metaremediation. J Environ Manage. 201, 120-128 (2017).

13. Rezaei, R., Akbulut, A. \& Sanin, S.L. Effect of algae acclimation to the wastewater medium on the growth kinetics and nutrient removal capacity. Environ Monit Assess. 191, 679 (2019).

14. Orfanos, A.G. \& Manariotis, I.D. Algal biofilm ponds for polishing secondary effluent and resource recovery. J App Phycol. 31, 1765-1772 (2019).

15. Powell, N., Shilton, A.N., Pratt, S. \& Chisti, Y. Factors influencing luxury uptake of phosphorus by microalgae in waste stabilization ponds. Environ. Sci. Technol. 42, 5958-5962 (2008).

16. Garbowski, T., Pietryka, M., Pulikowski, K. \& Richter, D. The use of a natural substrate for immobilization of microalgae cultivated in wastewater. Scientific Reports. 10, 7915 (2020).

17. Abdullah, B. et al. Fourth generation biofuel: a review on risks and mitigation strategies. Renew Sustain Energy Rev. 107, 37-50 (2019).

18. Sathe, S. \& Durand, P.M. A low cost, non-toxic biological method for harvesting algal biomass. Algal Res. 11, 169-172 (2015).

19. Califice, A., Michel, F., Dislaire, G. \& Pirard, E. Influence of particle shape on size distribution measurements by 3D and 2D image analyses and laser diffraction. Powder Technol. 237, 67-75 (2013).

20. Bawiec, A., Garbowski, T., Pawęska, K. \& Pulikowski, K. Analysis of the algae growth dynamics in the hydroponic system with LEDs nighttime lighting using the laser granulometry method. Water Air Soil Pollut. 230, 17 (2019).

21. Kuentz, M. \& Röthlisberger, D. Sedimentation analysis of aqueous microsuspensions based on near infrared transmission measurements during centrifugation. Determination of a suitable amount of gelling agent to minimize settling in the gravitational field. S. T.P. PHARMA SCIENCES. 12, 391-396 (2002).

22. Baliński A. Basic issues related to the measurement of size and particle size distribution. Transactions of Foundry Research Institute. LIII, 3-12 (2013).

23. Wiercik, P., Matras, K., Burszta-Adamiak, E. \& Kuśnierz, M. Analysis of the properties and particle size distribution of spent filter backwash water from groundwater treatment at various stages of filters washing. Engineering and Protection of Environment. 19, 149-161 (2016)

24. Kuśnierz, M. \& Wiercik, P. Analysis of particle size and fractal dimensions of suspensions contained in raw sewage, treated sewage and activated sludge. Arch. Environ. Prot. 42, 67-76 (2016). 
25. Valle, F., Brucale, M., Chiodini, S., Bystrenova, E. \& Albonetti, C. Nanoscale morphological analysis of soft matter aggregates with fractal dimension ranging from 1 to 3 . Micron. 100, 60-72 (2017).

26. Schroeder, L.D., Sjoquist, D.L. \& Stephan, P.E. Understanding regression analysis an introductory guide. (SAGE Publication Inc., 2016).

\section{Figures}

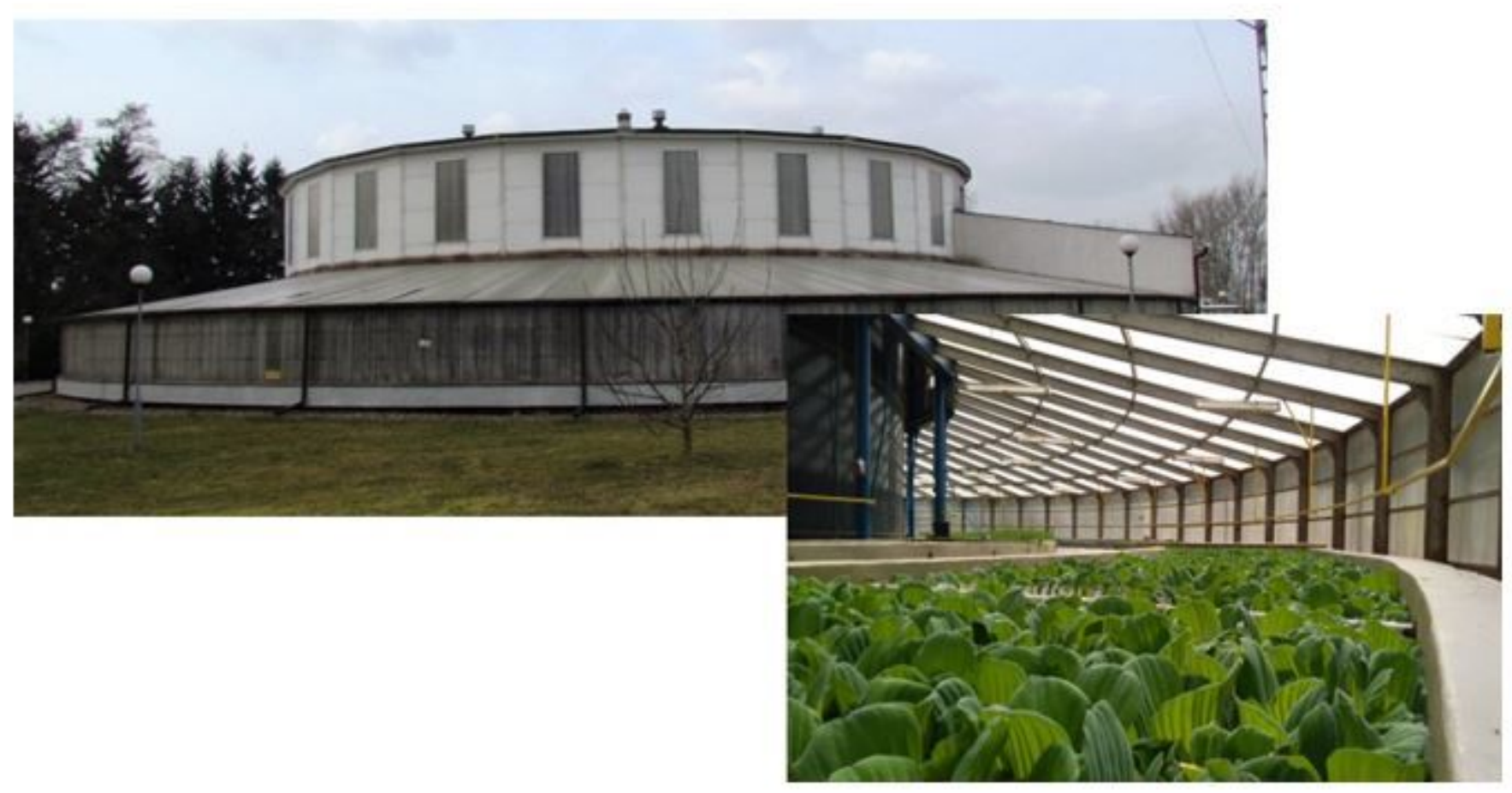

\section{Figure 1}

Municipal Wastewater Treatment Plant with hydroponic lagoon - WWTP A (phot. A. Bawiec) 


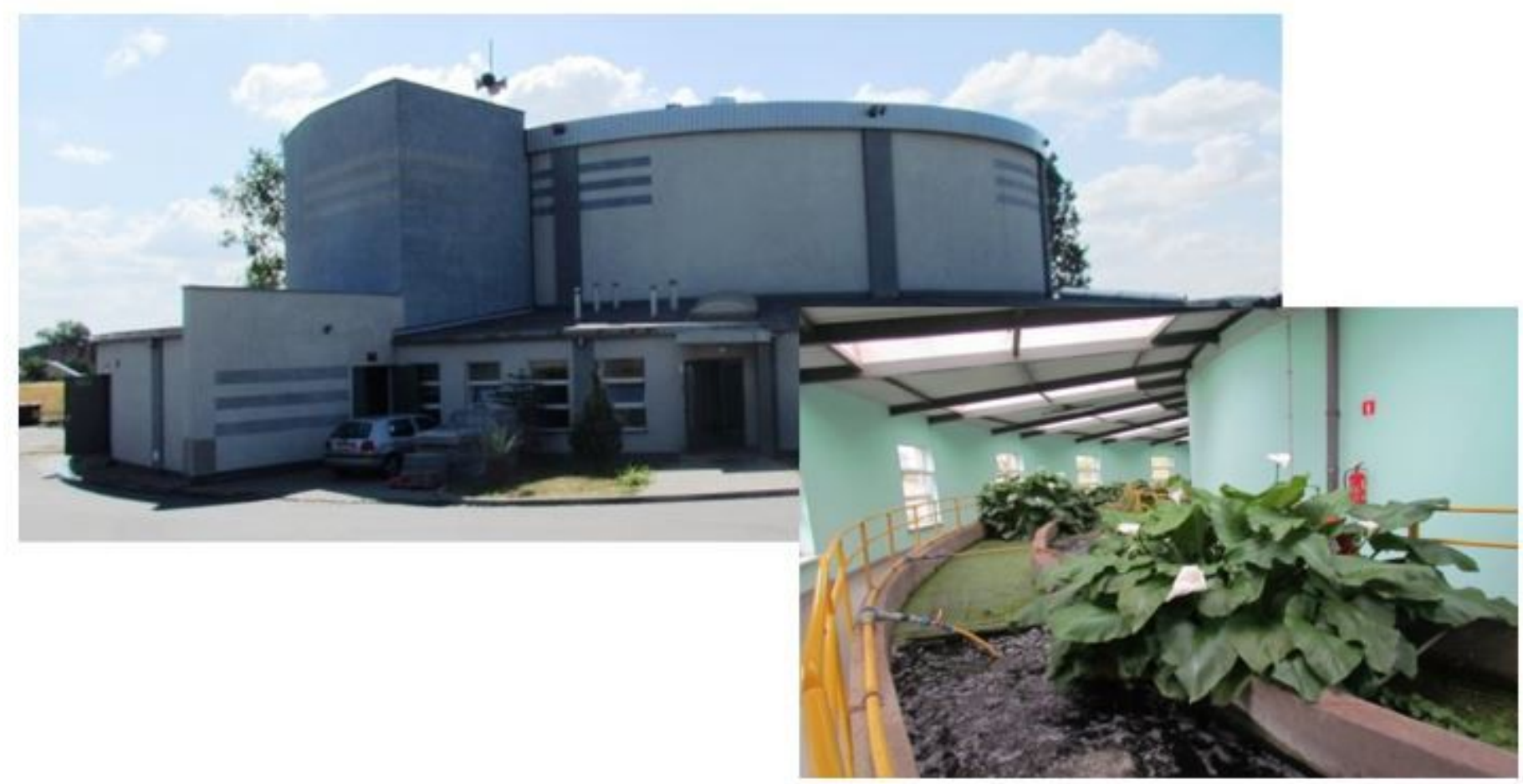

Figure 2

Municipal Wastewater Treatment Plant with hydroponic lagoon - WWTP B (phot. A. Bawiec)

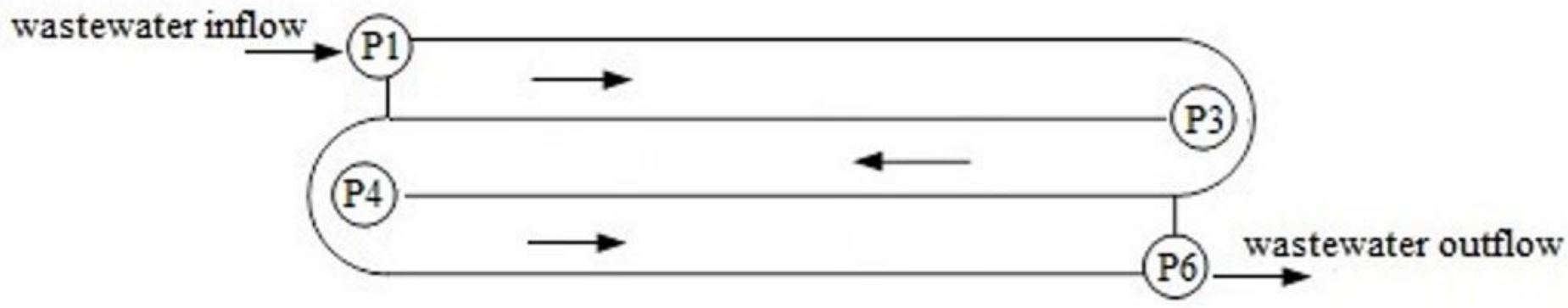

Figure 3

Scheme of hydroponic lagoon with sampling points (P1, P3, P4, P6) in WWTP A 

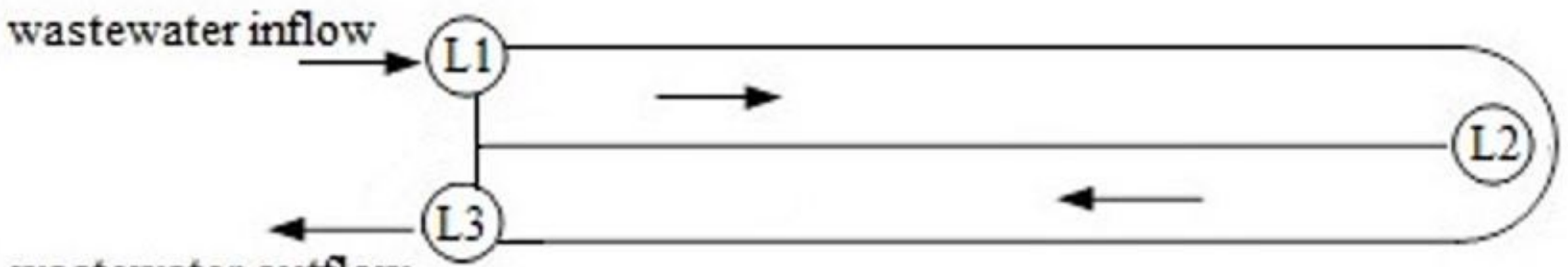

\section{wastewater outflow}

\section{Figure 4}

Scheme of hydroponic lagoon with sampling points (L1, L2, L3) in WWTP B

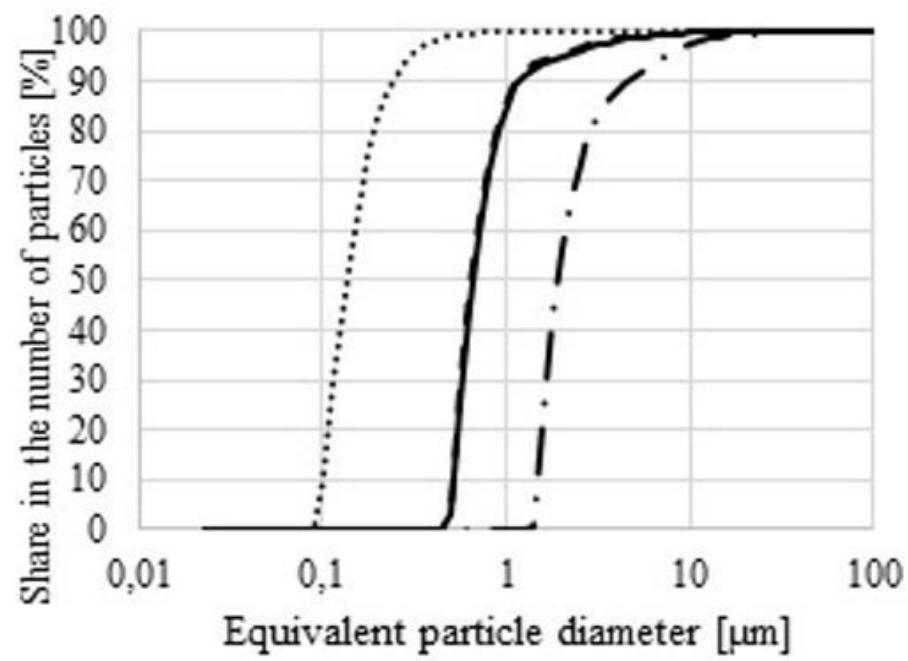

$\mathrm{A} \longrightarrow \mathrm{P} 1 \quad--\mathrm{P} 3 \quad \cdots \cdots \cdots \mathrm{P} 4 \quad-\cdots \mathrm{P} 6$

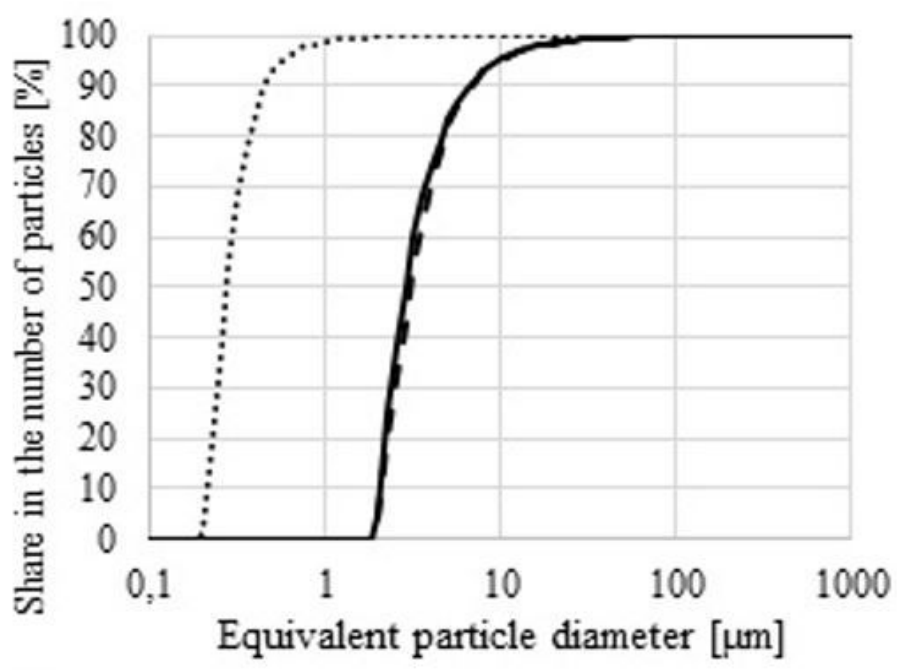

B

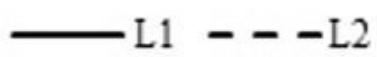

\section{Figure 5}

Percentage of particles with diameter di $[\mu \mathrm{m}]$ in the total number of suspended solids in the wastewater samples from hydroponic lagoon during winter season (WWTP A (A) and WWTP B (B)) 

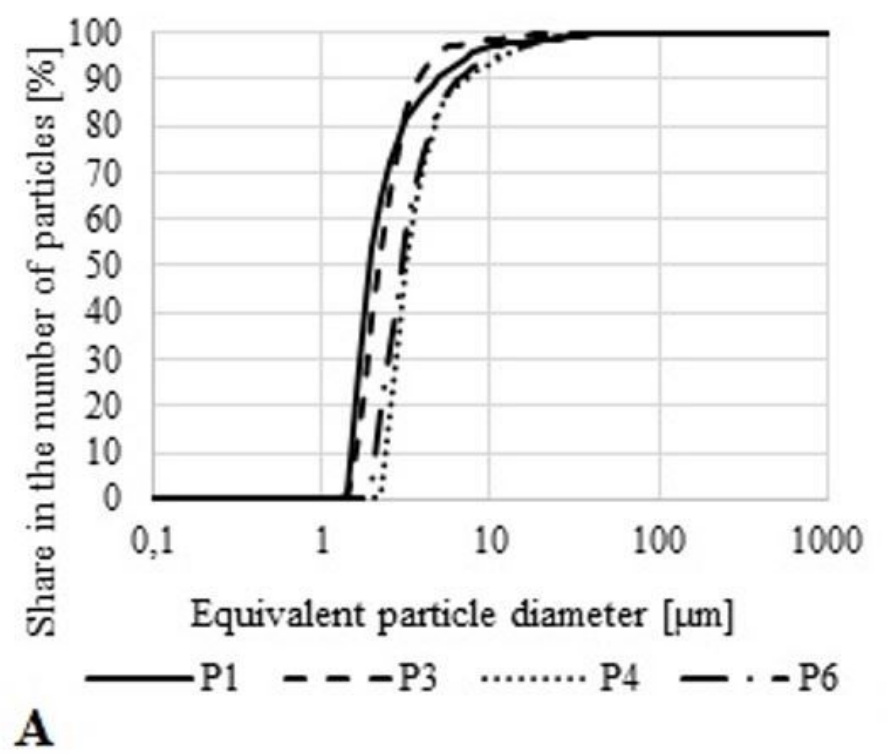

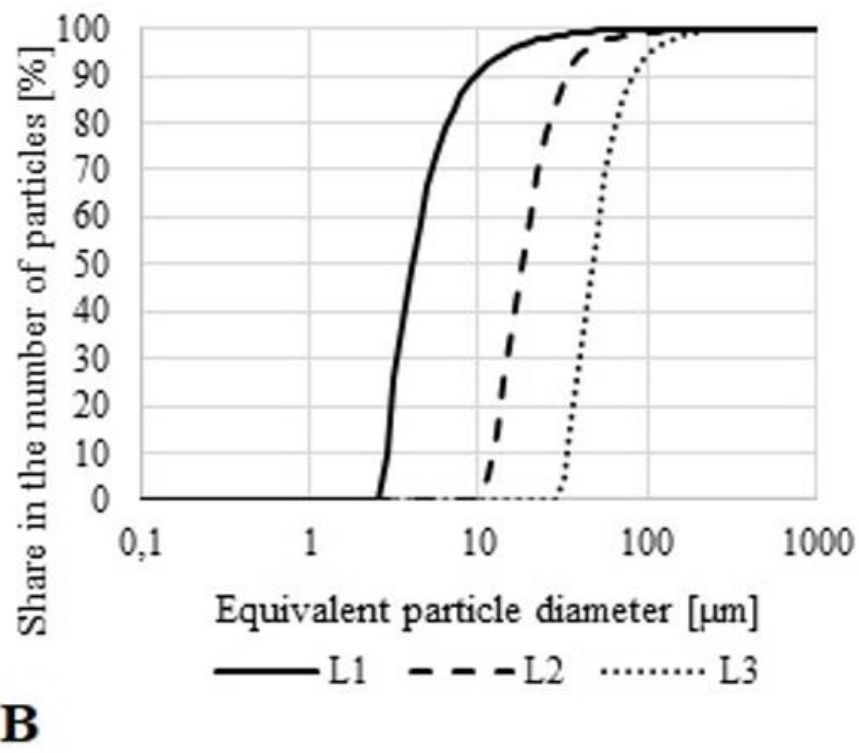

Figure 6

Percentage of particles with diameter di $[\mu \mathrm{m}]$ in the total number of suspended solids in the wastewater samples from hydroponic lagoon during summer season (WWTP A (A) and WWTP B (B))
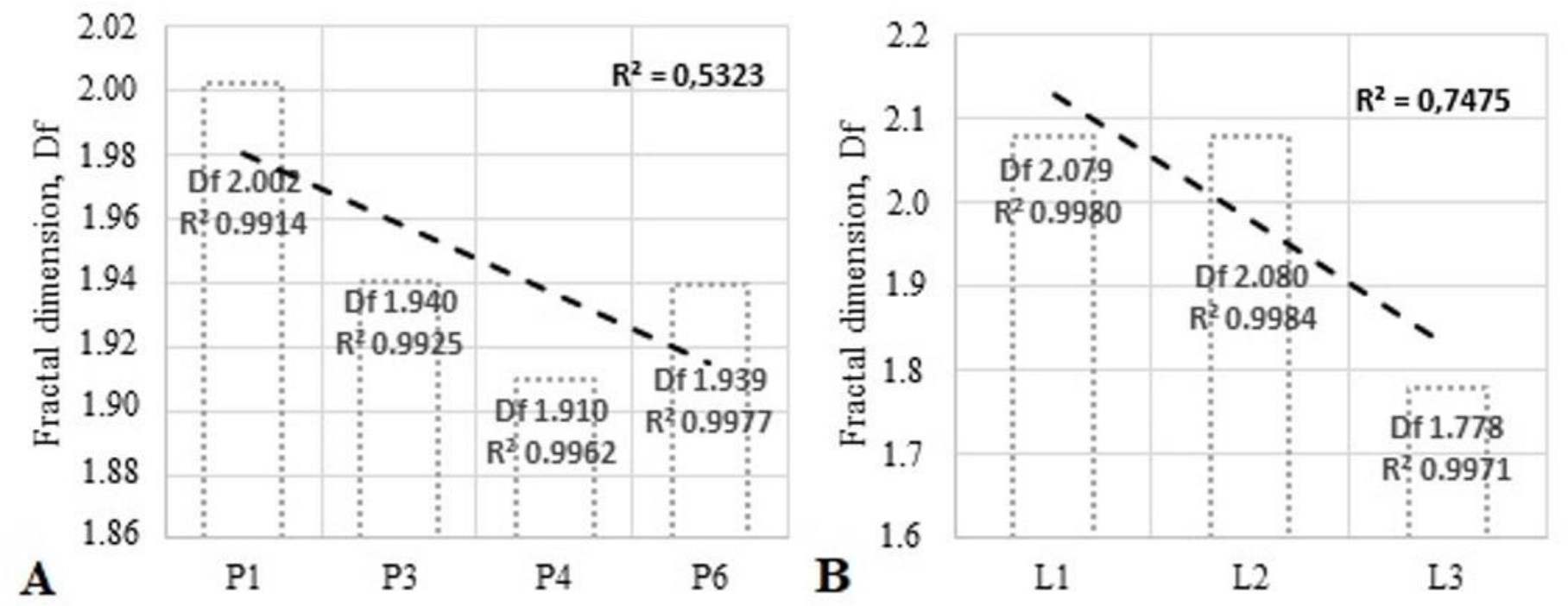

Figure 7

Average fractal dimensions (Df) of particles in the wastewater samples from hydroponic lagoon during winter season (WWTP A (A) and WWTP B (B)) 

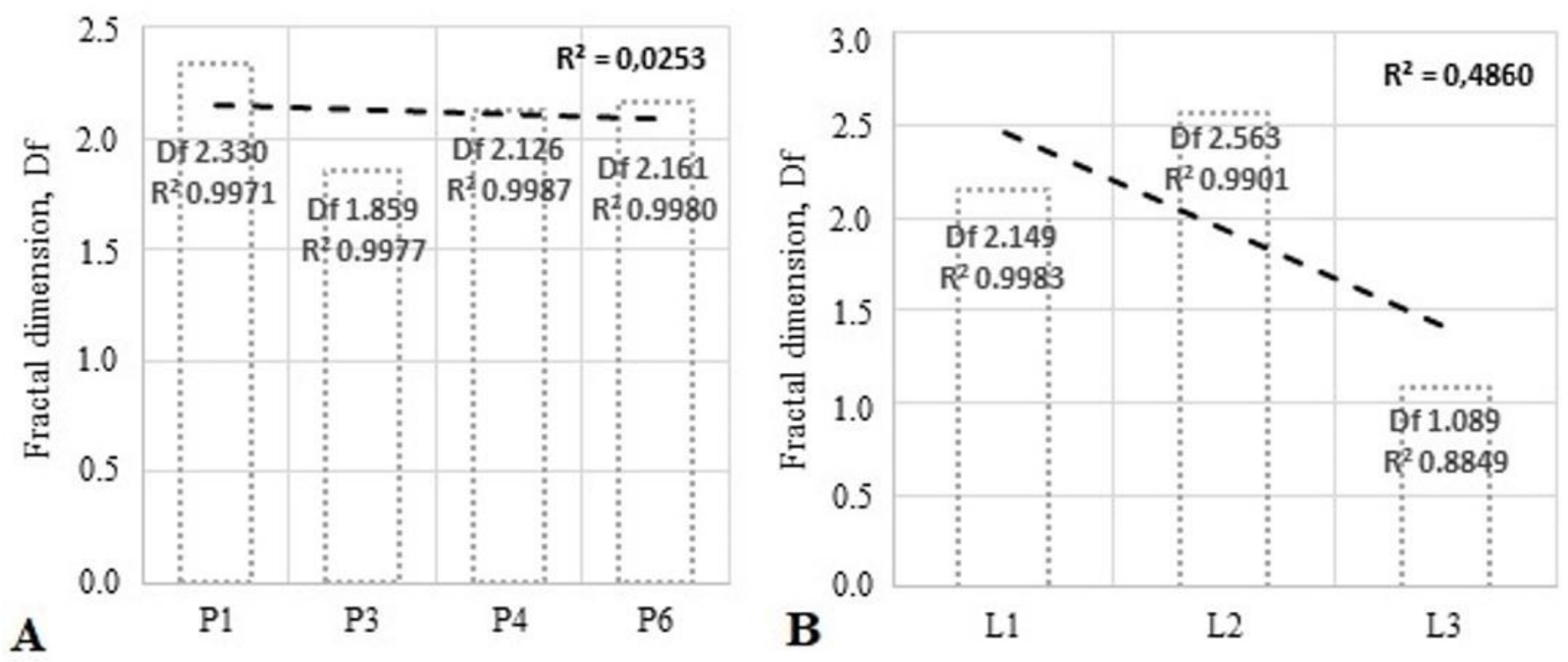

Figure 8

Average fractal dimensions (Df) of particles in the wastewater samples from hydroponic lagoon during summer season (WWTP A (A) and WWTP B (B)) 